\title{
Cervical sagittal alignment as a predictor of adjacent-level ossification development
}

This article was published in the following Dove Press journal: Journal of Pain Research

\section{Wei Liu* \\ Yuluo Rong* \\ Jian Chen* \\ Yongjun Luo \\ Pengyu Tang \\ Zheng Zhou \\ Jin Fan \\ Weihua Cai}

Department of Orthopaedic Surgery, The First Affiliated Hospital of Nanjing Medical University, Nanjing, Jiangsu 210029, China

*These authors contributed equally to this work
Correspondence: Jin Fan

Department of Orthopaedic Surgery, The First Affiliated Hospital of Nanjing Medical University, Nanjing, Jiangsu 210029, China

Email fanjingol@I26.com

Weihua Cai

Department of Orthopaedic Surgery, The First Affliated Hospital of Nanjing Medical University, 300 Guangzhou Road, Gulou Qu, Nanjing, Jiangsu 21 0029, China

Email caiwhspine@sina.com
Purpose: To explore the role of cervical sagittal alignment in the occurrence of adjacent-level ossification development (ALOD) in patients who underwent anterior cervical discectomy fusion with self-locking stand-alone polyetheretherketone cage, and the relationship between cervical sagittal alignment and clinical outcomes.

Background: Because of its advantages, anterior cervical plating systems have been used as the classic surgical method in the treatment of patients with cervical disc herniation. However, the proximity $(<5 \mathrm{~mm})$ of the plate to the adjacent disc space has proven to be a critical risk factor for ALOD. How cervical sagittal alignment influences the development of ALOD is unknown and its role in ALOD needs clarification.

Patients and methods: One hundred and eighteen adults who underwent anterior cervical discectomy fusion with self-locking stand-alone polyetheretherketone cage for cervical radiculopathy or myelopathy between December 2013 and December 2015 were retrospectively recruited. Of these, 15 patients developed ALOD and 103 patients did not, representing two groups for comparison. The cervical sagittal parameters were measured, including $\mathrm{C} 2-\mathrm{C} 7 \mathrm{Cobb}$ angle (Cobb), fused segment angle, cervical tilt (CT), T1 slope (T1S) and C2-C7 sagittal vertical axis. Clinical outcomes and efficacy were evaluated using a visual analog scale, Japanese Orthopedic Association (JOA) score and neck disability index (NDI) score before and after surgery. Results: There were no significant differences in patient demographics between the two groups. Cobb value $(P<0.05), \mathrm{CT}(P<0.05)$ and T1S $(P<0.05)$ were significantly different between the two groups, while fused segment angle $(P>0.05)$ and $\mathrm{C} 2-\mathrm{C} 7$ sagittal vertical axis $(P>0.05)$ showed no difference. Compared with preoperative scores, improvement was seen in postoperative visual analog scale, JOA and NDI scores at each time point $(P<0.05)$. However, the postoperative scores at 24 months in the NO-ALOD group indicated greater improvements compared with the ALOD group $(P<0.05)$. There were significant correlations between Cobb and CT $(r=0.607$, $P<0.05)$ and $\mathrm{CT}$ and T1S $(r=0.681, P<0.05)$. Also, T1S was significantly correlated with clinical outcomes (JOA: $r=0.689, P<0.05$; NDI: $r=-0.710, P<0.05$ ).

Conclusion: Maintaining a lordotic cervical sagittal alignment was related to a lower risk of ALOD and improved clinical outcomes.

Keywords: adjacent-level ossification development, cervical sagittal alignment, clinical outcomes, stand-alone anchored cage

\section{Introduction}

Degenerative conditions of the cervical spine, including cervical radiculopathy and myelopathy, are common in the orthopedic clinic. Surgical treatment of cervical radiculopathy or myelopathy is often required when conservative treatment 
is ineffective. Anterior cervical discectomy and fusion (ACDF) with plating and a cage system is an improved and widely accepted method for the treatment of degenerative cervical diseases, since its initial description by Smith and Robinson ${ }^{1}$ as well as Cloward. ${ }^{2}$ Anterior plate fixation can provide many benefits, including maintenance of intervertebral height and reduction of pseudarthrosis risk, and provides a high fusion rate and promotes cervical lordosis alignment. ${ }^{3-5}$ However, plating has been associated with higher rates of adjacent-level ossification development (ALOD) and dysphagia. ${ }^{6-10}$ ALOD is a type of heterotopic ossification in which new bone forms in soft tissues that do not ossify under normal conditions, rather than a secondary degeneration. Some studies have demonstrated a high incidence of ALOD in patients who have had cervical arthrodesis with plating, especially in those with a plate-to-disc distance $<5 \mathrm{~mm} .{ }^{8,10}$ The latest studies have demonstrated that a zero-profile integrated plate and spacer device and a zero-profile anchored spacer may result in a lower rate of ALOD compared with ACDF with plating and cage system. ${ }^{11-13}$ Also, one previous study ${ }^{14}$ demonstrated that excessive dissection of the anterior longitudinal ligament and incorrect placement of the plate could result in this phenomenon. Goffin et $\mathrm{al}^{15}$ recommend the use of as short a plate as possible to avoid the unwanted consequences of extending the plate excessively into adjacent discs. Park et $\mathrm{al}^{8}$ demonstrated that ALOD occurred with a higher frequency and with greater severity in patients when plates were located within $5 \mathrm{~mm}$ of an adjacent disc space, recommending the placement of anterior plates at least $5 \mathrm{~mm}$ away from the adjacent disc space to avoid the occurrence of ALOD. Yang et $\mathrm{al}^{16}$ found that patients who underwent anterior cervical arthrodesis without plate fixation had a significantly lower rate of ALOD compared with those with plate fixation. Lee et $\mathrm{al}^{17}$ recommended a new plating technique, which demonstrated unmatched advantages in the reduction in incidence and severity of ALOD using a short plate with an oblique screw trajectory angling the screws away from the end plates. However, the role of cervical sagittal alignment in the development of ALOD has not been reported on so far. In this study, we investigated whether a self-locking stand-alone polyetheretherketone (PEEK) cage (ROI-C or ROI-MC+; LDR, Sainte-Savine, France), which does not use anterior plate fixation, avoids the effects of anterior plate fixation on ALOD, and also studied the effect of cervical sagittal alignment on ALOD incidence.

\section{Patients and methods}

\section{Patient population}

The regional ethics review board of the First Affiliated Hospital of Nanjing Medical University approved the study, and all patients provided written informed consent. This study was conducted in accordance with the approved hospital guidelines. A total of 622 patients who experienced cervical radiculopathy or myelopathy between December 2013 and December 2015 were reviewed. The inclusion criteria were as follows: patients' age $\geq 20$ years; patients underwent ACDF with self-locking stand-alone PEEK cage; and patients followed up for $>2$ years. Patients who had undergone previous spinal surgery or who were diagnosed with other cervical diseases were excluded. Also, patients with invisible anatomic landmarks on X-ray, such as T1, were excluded. A total of 118 patients met the inclusion criteria. Of these, 15 patients diagnosed with ALOD at final follow-up were recruited as the ALOD group. The remaining 103 without ALOD were recruited as a NO-ALOD group. Demographic data collected included age at surgery, sex, body mass index (BMI), smoking status and Charlson comorbidity index (CCI). ${ }^{18}$ Surgical data were collected, including the number of surgical fusions at different levels.

\section{Cervical sagittal parameters}

A standing lateral radiograph of the cervical spine of each patient was obtained, with the patient in a comfortable standing position holding a horizontal gaze and the upper extremities naturally relaxed to the sides of the body. The presence of ALOD was verified on the plain lateral radiographs by two experienced spine surgeons independently. The curvature of the cervical spine was evaluated for lordotic, straight, kyphotic and sigmoid features according to a slight modification of the method proposed by Toyama et al. ${ }^{19}$ Cervical sagittal parameters were measured and evaluated on the cervical radiograph as follows: 1) $\mathrm{C} 2-\mathrm{C} 7 \mathrm{Cobb}$ angle (Cobb): the angle between the horizontal line of the $\mathrm{C} 2$ lower endplate and the horizontal line of the $\mathrm{C} 7$ lower endplate, measured using formal Cobb methods; 2) fused segment angle (FSA): measured using the Cobb angle between the cranial and caudal end plates of the fusion mass; 3) cervical tilt (CT): the angle between the line extending from the center of the T1 upper endplate (T1UEP) to the tip of the dens and the vertical line from the center of the T1UEP; 4) T1 slope (T1S): the angle between the T1UEP and the horizontal plate and 5) C2-C7 sagittal vertical axis (C2-C7 SVA): the distance between the vertical line from the center of the $\mathrm{C} 2$ body and the posterior superior corner of C7 (Figure 1). 

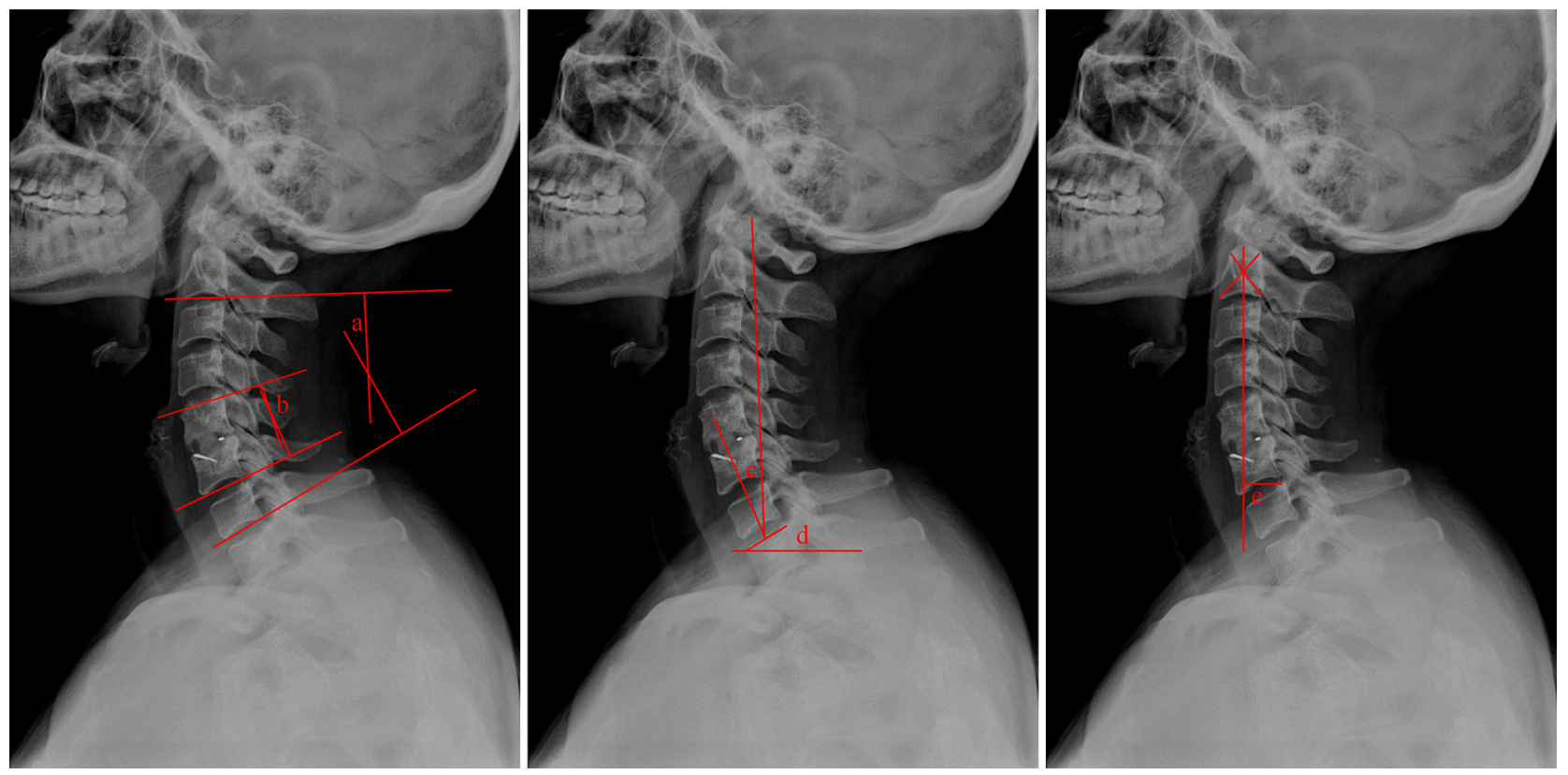

Figure I Cervical sagittal alignment measurements.

Note: a: C2-C7 Cobb angle (Cobb); b: the FSA; c: CT; d: TIS and e: C2-C7 SVA.

Abbreviations: C2-C7 SVA, C2-C7 sagittal vertical axis; CT, cervical tilt; FSA, fused segment angle; TIS, TI slope.

\section{Intra-observer reproducibility and inter- observer reliability of cervical sagittal parameter measurements}

To assess intra-observer reproducibility and inter-observer reliability of Cobb, FSA, CT, T1S and C2-C7 SVA, the measurements were tested and the agreement quantified using the intra-class correlation coefficient (ICC) and the median error for a single measurement (standard error of mean).

Two independent orthopedic spine surgeons with $>5$ years of experience in the field performed two series of cervical sagittal parameter measurements. The order in which the radiographs were evaluated was random in each of the two series, with a time span of 6 weeks between series.

An ICC value of $<0.40$ indicated poor agreement, $0.40-0.75$ indicated fair to good agreement and values $>0.75$ reflected excellent agreement. ${ }^{20}$

\section{Statistical analysis}

Measurements were recorded by the picture archiving and communication system in the hospital. SPSS Statistics for Windows, version 20.0 (IBM Corporation, Armonk, NY, USA) statistical software was used to analyze the measurement results, expressed as mean $\pm \mathrm{SD}(\mathrm{x} \pm \mathrm{s})$. For comparison of sex, BMI, smoking status, number of levels of surgery and curvature of the cervical spine, chi-squared test was used.
Independent sample $t$-test was used to compare the mean age, follow-up period and CCI. Comparisons of cervical sagittal parameter measurements between the ALOD and NO-ALOD groups and the visual analog scale (VAS), Japanese Orthopedic Association (JOA) score and neck disability index (NDI) score before and after surgery between the two groups were also made using independent sample $t$-tests. The correlation coefficients for intra-observer reproducibility and inter-observer reliability of cervical sagittal parameters measurements were evaluated using the Spearman correlation test, and Pearson correlation test was used to analyze the correlation between T1S, CT, Cobb, JOA and NDI. The correlation coefficient $r$ was calculated and linear regression used to establish linear models of the measurement results and clinical outcomes. $P<0.05$ was considered significant.

\section{Results}

\section{Demographics and operative details}

Preoperative age, sex, BMI, smoking status, number of levels of surgery, follow-up period and $\mathrm{CCI}$ in the two groups were not significantly different $(P>0.05)$; moreover, ALOD occurred in $11.6 \%$ of subjects in one-level ACDF group (5/43), $15.1 \%$ of subjects in two-level ACDF group (8/53) and in $9.1 \%$ of subjects in three-level ACDF group (2/22). This indicated that no significant difference in occurrence 
of ALOD was found between the number of fusion levels $(P>0.05)$. However, cervical spine curvature was significantly different $(P<0.05)$, as shown in Table 1.

There was excellent intra-observer reproducibility and inter-observer reliability for all the measured parameters. The lowest intra-rater ICC was 0.9 , for C2-C7 SVA, and the lowest inter-rater ICC was 0.81 , for FSA (Table 2). The results of Cobb, $\mathrm{CT}$ and T1S $(P<0.05)$ were significantly different between the two groups, while FSA and C2-C7 SVA $(P>0.05)$ showed no difference. Cobb, CT and T1S in the NO-ALOD group were significantly higher than in the ALOD group (Table 3), demonstrating that patients with a cervical spine with straighter curvature were more likely to have ALOD (Figure 2).

\section{Clinical outcomes}

The postoperative VAS, JOA and NDI scores at 3, 6, 12 and 24 months differed significantly from their respective preoperative VAS, JOA and NDI scores in both groups $(P<0.05)$. However, 24-month postoperative VAS, JOA and NDI scores showed greater improvement in the NO-ALOD group compared with the ALOD group $(P<0.05$; Table 4$)$. VAS and NDI scores in both groups declined rapidly at 3 and 6 months postoperatively, while JOA scores increased. VAS and NDI scores rebounded slightly and JOA scores fell back slightly at 12 and 24 months after surgery in both groups and these phenomena were more obvious in the ALOD group, with a significant difference at 24 months postoperatively compared with the NO-ALOD group $(P<0.05$; Figure 3$)$.

Table 2 Intra-rater and inter-rater ICC for all measurements

\begin{tabular}{lllll}
\hline & Intra-rater ICC & SEM & Inter-rater ICC & SEM \\
\hline Cobb & 0.96 & 1.53 & 0.91 & 1.37 \\
FSA & 0.93 & 2.07 & 0.81 & 2.32 \\
CT & 0.95 & 1.12 & 0.83 & 1.88 \\
TIS & 0.95 & 1.49 & 0.94 & 1.14 \\
C2-C7 SVA & 0.9 & 1.98 & 0.86 & 2.07 \\
\hline
\end{tabular}

Abbreviations: C2-C7 SVA, C2-C7 sagittal vertical axis; CT, cervical tilt; FSA, fused segment angle; SEM, standard error of the mean; TIS, TI slope.

Table 3 Comparison of the cervical sagittal alignment measurements of the NO-ALOD and ALOD groups

\begin{tabular}{llll}
\hline & NO-ALOD & ALOD & P-value \\
\hline Cobb $\left(^{\circ}\right)$ & $15.30 \pm 10.36$ & $8.82 \pm 9.78$ & $<0.05$ \\
FSA $\left(^{\circ}\right)$ & $2.70 \pm 5.67$ & $1.03 \pm 3.79$ & $>0.05$ \\
CT $\left(^{\circ}\right)$ & $22.32 \pm 7.00$ & $18.25 \pm 5.59$ & $<0.05$ \\
TIS $\left(^{\circ}\right)$ & $26.24 \pm 6.42$ & $21.89 \pm 4.66$ & $<0.05$ \\
C2-C7 SVA $(m m)$ & $13.84 \pm 7.24$ & $12.45 \pm 9.06$ & $>0.05$ \\
\hline
\end{tabular}

Abbreviations: ALOD, adjacent-level ossification development; C2-C7 SVA, C2-C7 sagittal vertical axis; CT, cervical tilt; FSA, fused segment angle; TIS, TI slope.

Table I Demographics, operative details and cervical spine curvature of the NO-ALOD and ALOD groups

\begin{tabular}{|c|c|c|c|}
\hline & NO-ALOD & ALOD & $P$-value \\
\hline Number & 103 & 15 & \\
\hline Mean age (years) & $51.62 \pm 10.09$ & $52.53 \pm 6.61$ & $>0.05$ \\
\hline \multicolumn{4}{|l|}{ Sex } \\
\hline Male & 49 & 6 & $>0.05$ \\
\hline Female & 54 & 9 & \\
\hline \multicolumn{4}{|l|}{ BMI $\left(\mathrm{kg} / \mathrm{m}^{2}\right)$} \\
\hline$<30$ & 60 & 8 & $>0.05$ \\
\hline$>30$ & 43 & 7 & \\
\hline \multicolumn{4}{|l|}{ Smoking status } \\
\hline Non-smoker & 79 & 12 & $>0.05$ \\
\hline Smoker & 24 & 3 & \\
\hline \multicolumn{4}{|l|}{ Number of levels } \\
\hline 1 & 38 & 5 & $>0.05$ \\
\hline 2 & 45 & 8 & \\
\hline 3 & 20 & 2 & \\
\hline Follow-up period (months) & $37.86 \pm 9.47$ & $36.80 \pm 10.60$ & $>0.05$ \\
\hline $\mathrm{CCl}$ & $2.76 \pm 1.34$ & $3.07 \pm 1.22$ & $>0.05$ \\
\hline \multicolumn{4}{|l|}{ Curvature of cervical spine } \\
\hline Lordotic & 74 & 4 & $<0.05$ \\
\hline Straight & 23 & 6 & \\
\hline Kyphotic & 6 & 5 & \\
\hline
\end{tabular}

Note: Cervical sagittal parameter measurements.

Abbreviations: ALOD, adjacent-level ossification development; $\mathrm{BMI}$, body mass index; $\mathrm{CCl}$, Charlson comorbidity index. 

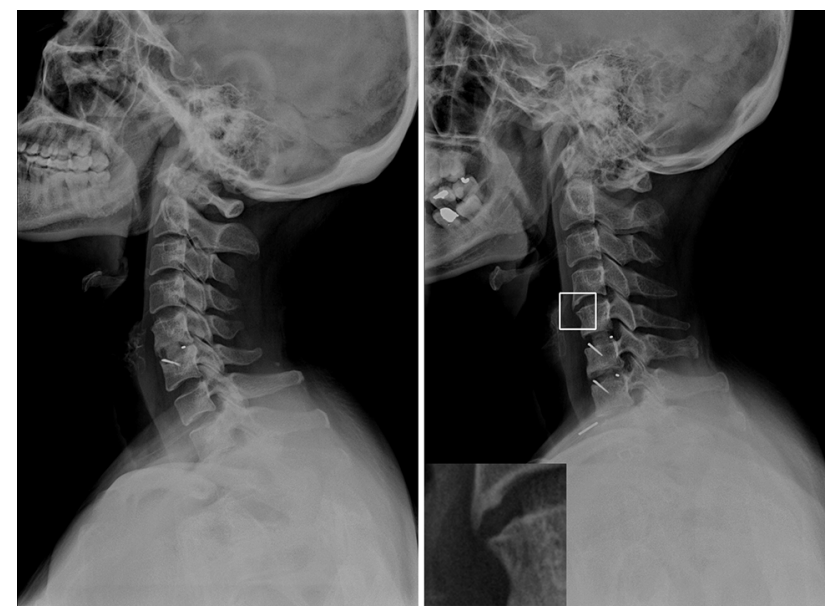

Figure 2 Representative images of NO-ALOD and ALOD at the final follow-up. Abbreviation: ALOD, adjacent-level ossification development.

There was significant correlation between Cobb and CT $(r=0.607, P<0.05)$, and CT and T1S $(r=0.681, P<0.05)$. Also, T1S was significantly correlated with clinical outcomes (JOA: $r=0.689, P<0.05$; NDI: $r=-0.710, P<0.05$ ), as shown in Table 5 and Figure 4.

\section{Discussion}

ACDF, which classically includes the use of autograft and external immobilization, is the gold standard for the treatment of cervical radiculopathy or myelopathy and has attractive advantages in increasing the bone graft fusion rate, maintaining cervical lordosis and reducing the period of immobilization. ${ }^{21-23}$ However, ALOD has been shown in some studies to occur with increased frequency after anterior cervical arthrodesis with plating. ${ }^{8}{ }^{89}$ All the studies thus far were concerned with cervical arthrodesis with or without plate fixation and the distance between the plates and the adjacent discs, while neglecting the effect of cervical sagittal alignment on ALOD. Thus, we conducted a study that mainly focused on the effect of cervical sagittal alignment on the occurrence of ALOD.

The prevalence of clinical ALOD has been reported to be between $41 \%$ and $64 \%$ in ACDF with anterior plate fixation, $24 \%$ with cervical intervertebral arthroplasty and $6 \%$ without plate fixation. ${ }^{8,9,16,24}$ We studied the impact of self-locking stand-alone PEEK cage only without anterior plate fixation on the occurrence of ALOD. According to our analysis, ALOD incidence was $12.7 \%$ (15/118), which was far lower than that for conventional anterior plate fixation. Meanwhile, we found surprising significant differences in the incidence of cervical spine curvature between the NO-ALOD and ALOD groups, including lordosis (71.8\% vs $26.7 \%)$, straight $(22.3 \%$ vs $40 \%)$ and kyphosis $(5.8 \%$ vs $33.3 \%)$. Therefore, we determined whether postoperative cervical sagittal alignment, measured by Cobb, FSA, CT, T1S and C2-C7 SVA, was associated with the occurrence of ALOD after anterior cervical arthrodesis.

The results showed that Cobb, CT and T1S were significant higher in the NO-ALOD group compared with the ALOD group, while FSA and C2-C7 SVA showed no difference between the two groups. We searched through the relevant literature and found no previous reports on the
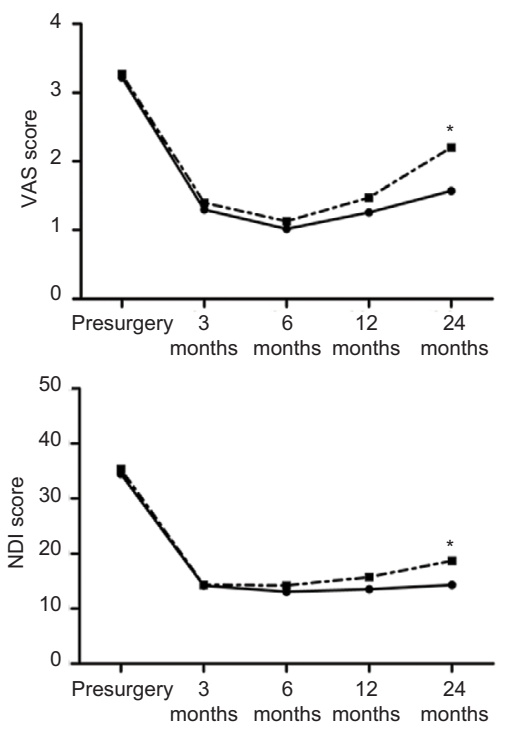

$\rightarrow$ NO-ALOD

-.. ALOD

$\rightarrow$ NO-ALOD

- ALOD

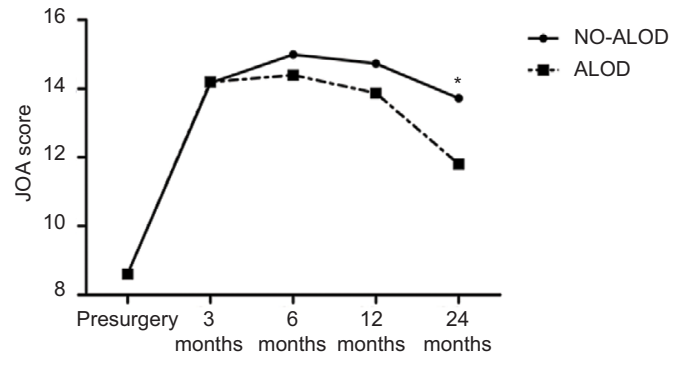

Figure $3 \mathrm{VAS}, \mathrm{JOA}$ and NDI scores before and after surgery.

Note: $* P<0.05$ between NO-ALOD and ALOD groups.

Abbreviations: ALOD, adjacent-level ossification development; JOA, Japanese Orthopedic Association; NDI, neck disability index; VAS, visual analog scale. 
Table 4 Clinical outcomes before and after surgery

\begin{tabular}{llll}
\hline & VAS score & JOA score & NDI score \\
\hline NO-ALOD & & & $34.49 \pm 4.44$ \\
Presurgery & $3.22 \pm 0.95$ & $8.62 \pm 1.29$ & $14.17 \pm 4.03^{\mathrm{a}}$ \\
3 months postsurgery & $1.30 \pm 0.74^{\mathrm{a}}$ & $14.17 \pm 1.57^{\mathrm{a}}$ & $13.05 \pm 3.33^{\mathrm{a}}$ \\
6 months postsurgery & $1.02 \pm 0.78^{\mathrm{a}}$ & $14.99 \pm 1.65^{\mathrm{a}}$ & $13.53 \pm 4.14^{\mathrm{a}}$ \\
12 months postsurgery & $1.26 \pm 0.69^{\mathrm{a}}$ & $14.73 \pm 1.84^{\mathrm{a}}$ & $14.32 \pm 5.74^{\mathrm{a}}$ \\
24 months postsurgery & $1.57 \pm 0.80^{\mathrm{a}}$ & $13.71 \pm 2.5 \mathrm{I}^{\mathrm{a}}$ & \\
ALOD & & & $35.40 \pm 4.50$ \\
Presurgery & $3.27 \pm 0.70$ & $8.60 \pm 0.99$ & $14.33 \pm 4.70^{\mathrm{a}}$ \\
3 months postsurgery & $1.40 \pm 0.63^{\mathrm{a}}$ & $14.20 \pm 1.42^{\mathrm{a}}$ & $14.20 \pm 1.82^{\mathrm{a}}$ \\
6 months postsurgery & $1.13 \pm 0.74^{\mathrm{a}}$ & $14.40 \pm 1.45^{\mathrm{a}}$ & $15.73 \pm 5.47^{\mathrm{a}}$ \\
12 months postsurgery & $1.47 \pm 0.64^{\mathrm{a}}$ & $13.87 \pm 1.8 \mathrm{I}^{\mathrm{a}}$ & $18.67 \pm 7.34^{\mathrm{a}, \mathrm{b}}$ \\
24 months postsurgery & $2.20 \pm 0.77^{\mathrm{a}, \mathrm{b}}$ & $11.80 \pm 3.10^{\mathrm{a}, \mathrm{b}}$ & \\
\hline
\end{tabular}

Note: ${ }^{a} P<0.05$ vs presurgery; ${ }^{b} P<0.05$ between NO-ALOD and ALOD groups.

Abbreviations: ALOD, adjacent-level ossification development; JOA, Japanese Orthopedic Association; NDI, neck disability index; VAS, visual analog scale.

Table 5 Correlation between cervical sagittal parameters and clinical outcomes

\begin{tabular}{llllll}
\hline & TIS & CT & Cobb & JOA & NDI \\
\hline TIS & $\mathrm{I}$ & $0.68 \mathrm{I}^{\mathrm{a}}$ & $0.460^{\mathrm{a}}$ & $0.689^{\mathrm{a}}$ & $-0.710^{\mathrm{a}}$ \\
CT & & $\mathrm{I}$ & $0.607^{\mathrm{a}}$ & $0.504^{\mathrm{a}}$ & $-0.440^{\mathrm{a}}$ \\
Cobb & & & $\mathrm{I}$ & $0.353^{\mathrm{a}}$ & $-0.322^{\mathrm{a}}$ \\
JOA & & & & $\mathrm{I}$ & $-0.620^{\mathrm{a}}$ \\
NDI & & & & & $\mathrm{I}$ \\
\hline
\end{tabular}

Note: ${ }^{a} P<0.05$.

Abbreviations: CT, cervical tilt; JOA, Japanese Orthopedic Association; NDI, neck disability index; TIS, TI slope.

relationship between cervical sagittal alignment and ALOD. It is generally accepted that physiological cervical sagittal balance is important for normal spine function, and the maintenance of and improvements to cervical spine function are bound to have an effect on clinical efficacy and outcomes. ${ }^{25,26}$ As a result, an increased risk of adjacent segment diseases such as adjacent segment degeneration and ALOD may be due to malalignment of the cervical spine postoperatively. ${ }^{27}$ A previous study applied the osteophyte and periarticular ossicle formation, cartilage narrowing with subchondral bone sclerosis, pseudocystic areas and altered bone shape viewed on the radiograph as evidence of degeneration ${ }^{28}$ and found that malalignment after cervical arthrodesis promoted degenerative changes at levels adjacent to the fused segment. ${ }^{27}$ A similar finding by Katsuura et $\mathrm{al}^{29}$ indicated that overall cervical sagittal alignment in the postoperative radiograph was more kyphotic in patients with radiographically apparent adjacent-level degeneration. Although ALOD may not have the same definition as other adjacent segment pathology, we have reliable reasons to believe that the malalignment after anterior cervical surgery may have a relationship with ALOD.
In terms of clinical efficacy, both groups in this study showed a trend of significant improvement in the first 6 months after surgery, but a slight recessive trend after 1 year. We suspected that after cervical arthrodesis, decreased cervical vertebrae activity, increased stress to the adjacent segment, pedicle screw looseness and accelerated adjacent segment degeneration were responsible for decline in clinical efficiency at 12 months postsurgery. Our study showed great clinical efficiency in the NO-ALOD group than in the ALOD group postsurgery. We attributed this phenomenon to malalignment in the cervical spine after surgery in the ALOD group. Meanwhile, we found that T1S was significantly correlated with $\mathrm{CT}$, while $\mathrm{CT}$ was significantly correlated with Cobb. Therefore, we hypothesize that an increased T1S results in an increased $\mathrm{CT}$, and an increased CT then results in an increased Cobb, and that these three cervical sagittal parameters contribute to an increased lordotic cervical curvature. Also, clinical efficacy, demonstrated by JOA and NDI scores, was significantly correlated with T1S. As T1S increases, increased clinical efficacy postsurgery might be expected. In all, our study indicated that maintaining a lordotic cervical sagittal alignment postsurgery showed a lower risk of occurrence in ALOD and better clinical outcomes. Spine surgeons should pay attention to correcting and maintaining the cervical alignment in spine surgery in order to lower the incidence of ALOD and improve the clinical outcomes.

\section{Limitations}

The study had inevitable limitations. First, the number of patients in the ALOD group was relatively small compared with the NO-ALOD group. Second, the study mainly focused 

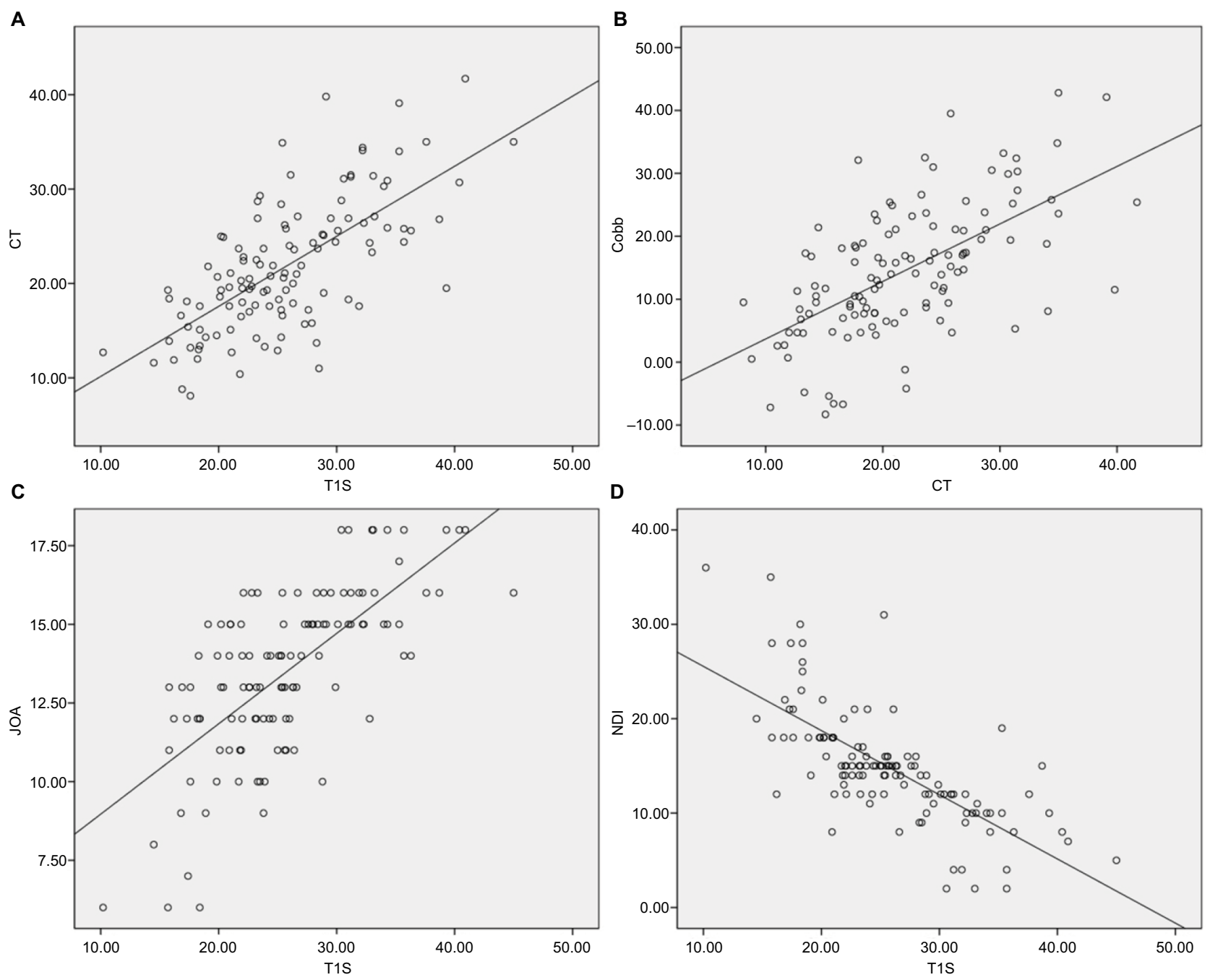

Figure 4 Linear regression analysis of cervical sagittal parameters and clinical outcomes.

Note: (A-D) Linear regression analysis comparing TIS and CT, CT and Cobb, TIS and JOA, and TIS and NDI, respectively.

Abbreviations: CT, cervical tilt; JOA, Japanese Orthopedic Association; NDI, neck disability index; TIS, TI slope.

on postoperative cervical sagittal alignment and incidence of ALOD and not preoperative cervical alignment or changes in cervical alignment. Furthermore, this was a retrospective study lacking strict randomized control; thus, further largescale study is recommended.

\section{Conclusion}

Maintaining a lordotic cervical sagittal alignment was related to a lower risk of ALOD and improved clinical outcomes.

\section{Acknowledgments}

This work was sponsored by the National Natural Science Foundation of China (grant no. 81772352), the Wu Jieping Foundation (grant no. 320-2745-16-117), the "333 High Level Talents Project” in Jiangsu Province, China (grant no. BRA2016512) and the Jiangsu Province Six Talents Peak from Department of Human Resources, Social Security Office of Jiangsu Province, China (grant no. 2014-WSN-012).

\section{Disclosure}

The authors report no conflicts of interest in this work.

\section{References}

1. Smith GW, Robinson RA. The treatment of certain cervical-spine disorders by anterior removal of the intervertebral disc and interbody fusion. J Bone Joint Surg Am. 1958;40-A(3):607-624.

2. Cloward RB. The anterior approach for removal of ruptured cervical disks. J Neurosurg. 1958;15(6):602-617.

3. Song KJ, Taghavi CE, Lee KB, Song JH, Eun JP. The efficacy of plate construct augmentation versus cage alone in anterior cervical fusion. Spine. 2009;34(26):2886-2892. 
4. Silber JS, Anderson DG, Daffner SD, et al. Donor site morbidity after anterior iliac crest bone harvest for single-level anterior cervical discectomy and fusion. Spine. 2003;28(2):134-139.

5. Kim SW, Limson MA, Kim SB, et al. Comparison of radiographic changes after ACDF versus Bryan disc arthroplasty in single and bilevel cases. Eur Spine J. 2009;18(2):218-231.

6. Fountas KN, Kapsalaki EZ, Nikolakakos LG, et al. Anterior cervical discectomy and fusion associated complications. Spine. 2007;32(21): 2310-2317.

7. Riley LH, Skolasky RL, Albert TJ, Vaccaro AR, Heller JG. Dysphagia after anterior cervical decompression and fusion: prevalence and risk factors from a longitudinal cohort study. Spine. 2005;30(22): 2564-2569.

8. Park JB, Cho YS, Riew KD. Development of adjacent-level ossification in patients with an anterior cervical plate. J Bone Joint Surg Am. 2005;87(3):558-563.

9. Garrido BJ, Wilhite J, Nakano M, et al. Adjacent-level cervical ossification after Bryan cervical disc arthroplasty compared with anterior cervical discectomy and fusion. J Bone Joint Surg Am. 2011;93(13): 1185-1189.

10. Park JB, Watthanaaphisit T, Riew KD. Timing of development of adjacent-level ossification after anterior cervical arthrodesis with plates. Spine J. 2007;7(6):633-636.

11. Yang H, Chen D, Wang X, Yang L, He H, Yuan W. Zero-profile integrated plate and spacer device reduces rate of adjacent-level ossification development and dysphagia compared to ACDF with plating and cage system. Arch Orthop Trauma Surg. 2015;135(6):781-787.

12. Bucci MN, Oh D, Cowan RS, et al. The ROI-C zero-profile anchored spacer for anterior cervical discectomy and fusion: biomechanical profile and clinical outcomes. Med Devices. 2017;10:61-69.

13. Liu Y, Wang H, Li X, et al. Comparison of a zero-profile anchored spacer (ROI-C) and the polyetheretherketone (PEEK) cages with an anterior plate in anterior cervical discectomy and fusion for multilevel cervical spondylotic myelopathy. Eur Spine J. 2016;25(6):1881-1890.

14. Mähring M. Segment changes in the cervical spine following cervical spondylodeses of unstable injuries. Unfallchirurgie. 1988;14(5): $247-258$.

15. Goffin J, van Loon J, van Calenbergh F, Plets C. Long-term results after anterior cervical fusion and osteosynthetic stabilization for fractures and/or dislocations of the cervical spine. J Spinal Disord. 1995;8(6):500-508; discussion 499.

16. Yang JY, Song HS, Lee M, Bohlman HH, Riew KD. Adjacent level ossification development after anterior cervical fusion without plate fixation. Spine. 2009;34(1):30-33.
17. Lee DH, Lee JS, Yi JS, Cho W, Zebala LP, Riew KD. Anterior cervical plating technique to prevent adjacent-level ossification development. Spine J. 2013;13(7):823-829.

18. Charlson M, Szatrowski TP, Peterson J, Gold J. Validation of a combined comorbidity index. J Clin Epidemiol. 1994;47(11):1245-1251.

19. Toyama Y, Matsumoto M, Chiba K, et al. Realignment of postoperative cervical kyphosis in children by vertebral remodeling. Spine. 1994;19(22):2565-2570.

20. Streiner DL, Norman GR. Health Measurement Scales : A Practical Guide to Their Development and Use. Oxford ; New York: Oxford University Press; 2008.

21. Li J, Zheng Q, Guo X, et al. Anterior surgical options for the treatment of cervical spondylotic myelopathy in a long-term follow-up study. Arch Orthop Trauma Surg. 2013;133(6):745-751.

22. Wang JC, Mcdonough PW, Kanim LE, Endow KK, Delamarter RB. Increased fusion rates with cervical plating for three-level anterior cervical discectomy and fusion. Spine. 2001;26(6):643-646.

23. Vanichkachorn J, Peppers T, Bullard D, Stanley SK, Linovitz RJ, Ryaby JT. A prospective clinical and radiographic 12-month outcome study of patients undergoing single-level anterior cervical discectomy and fusion for symptomatic cervical degenerative disc disease utilizing a novel viable allogeneic, cancellous, bone matrix (trinity evolution ${ }^{\mathrm{TM}}$ ) with a comparison to historical controls. Eur Spine J. 2016;25(7):2233-2238.

24. Park Y, Maeda T, Cho W, Riew KD. Comparison of anterior cervical fusion after two-level discectomy or single-level corpectomy: sagittal alignment, cervical lordosis, graft collapse, and adjacent-level ossification. Spine J. 2010;10(3):193-199.

25. Villavicencio AT, Babuska JM, Ashton A, et al. Prospective, Randomized, Double-Blind Clinical Study Evaluating the Correlation of Clinical Outcomes and Cervical Sagittal Alignment. Neurosurgery. 2011;68(5):1309-1316; discussion 1316-1316.

26. Tang JA, Scheer JK, Smith JS, et al. The impact of standing regional cervical sagittal alignment on outcomes in posterior cervical fusion surgery. Neurosurgery. 2012;71(3):662-669.

27. Park MS, Kelly MP, Lee DH, Min WK, Rahman RK, Riew KD. Sagittal alignment as a predictor of clinical adjacent segment pathology requiring surgery after anterior cervical arthrodesis. Spine J. 2014;14(7):1228-1234.

28. Kellgren JH, Lawrence JS. Radiological assessment of osteo-arthrosis. Ann Rheum Dis. 1957;16(4):494-502.

29. Katsuura A, Hukuda S, Saruhashi Y, Mori K. Kyphotic malalignment after anterior cervical fusion is one of the factors promoting the degenerative process in adjacent intervertebral levels. Eur Spine J. 2001;10(4):320-324.
Journal of Pain Research

\section{Publish your work in this journal}

The Journal of Pain Research is an international, peer reviewed, open access, online journal that welcomes laboratory and clinical findings in the fields of pain research and the prevention and management of pain. Original research, reviews, symposium reports, hypothesis formation and commentaries are all considered for publication.

\section{Dovepress}

The manuscript management system is completely online and includes a very quick and fair peer-review system, which is all easy to use. Visit http://www.dovepress.com/testimonials.php to read real quotes from published authors. 